\title{
KESIMILARAN SEMU PADA MATRIKS FUZZY
}

\author{
DUHAIFA ANESSA, NOVA NOLIZA BAKAR, MONIKA RIANTI HELMI \\ Program Studi S1 Matematika, \\ Fakultas Matematika dan Ilmu Pengetahuan Alam, Universitas Andalas, \\ Kampus UNAND Limau Manis Padang, Indonesia, \\ email: duhaifa.anessa@gmail.com
}

\begin{abstract}
Abstrak. Matriks fuzzy adalah matriks yang entri-entrinya berada pada selang tutup $[0,1]$. Pada tulisan ini akan membahas tentang sifat-sifat yang bersesuaian dengan kesi milaran semu pada matriks fuzzy $A$ dan $B$. Selanjutnya, diperoleh sifat-sifat yang ber sesuaian dengan kesimilaran semu pada matriks fuzzy $A$ dan $B$ yaitu misalkan $A$ dan $B$ adalah matriks fuzzy masing-masing berukuran $m \times m$ dan $n \times n$ sedemikian sehingga $A$ similar $B$, maka (1) $A$ adalah matriks regular jika dan hanya jika $B$ adalah matriks regular. (2) $A$ adalah idempoten jika dan hanya jika $B$ adalah idempoten.
\end{abstract}

Kata Kunci: Matriks fuzzy, kesimilaran semu, similar, matriks regular, idempoten

$\begin{array}{lll}\text { Diterima } & : & \text { 26 Juli 2018 } \\ \text { Direvisi } & : & 17 \text { September } 2018 \\ \text { Dipublikasikan } & : & 21 \text { Desember 2018 }\end{array}$

\section{Pendahuluan}

Matriks fuzzy didefinisikan pertama kali oleh Thomson pada tahun 1977 [3], kemudian teori dari matriks fuzzy dikembangkan oleh Kim dan Roush dan dilanjutkan dengan komposisi max-min matriks Boolean [2]. Operasi-operasi pada matriks fuzzy menggunakan operasi max-min dan berbeda dengan operasi matriks atas bilangan real dan kompleks.

Pada matriks fuzzy terdapat konsep generalisasi invers ( $g$-invers). Generalisasi invers ( $g$-invers)merupakan perluasan dari konsep invers matriks yang dideskripsikan oleh E.H Moore pada tahun 1920. Kemudian pada tahun 1955 Roger Penrose berhasil mendeskripsikan empat persamaan yang harus dipenuhi untuk menentukan $g$-invers [1]. Persamaan tersebut dikenal dengan nama persamaan Penrose. Tulisan ini akan menjelaskan definisi dan sifat-sifat yang bersesuaian dengan kesimilaran semu pada matriks fuzzy $A$ dan $B$.

\section{Landasan Teori}

Pada bagian ini akan dijelaskan operasi penjumlahan dan perkalian pada aljabar dan karakteristik yang terkait dengan operasi penjumlahan dan perkalian fuzzy.

Definisi 2.1. [6] Misalkan $a, b \in F$ dimana $F=[0,1]$ maka operasi penjumlahan dan perkalian pada $a, b$ didefinisikan sebagai berikut,

$$
a+b=\max \{a, b\}, \quad a \cdot b=\min \{a, b\} .
$$


Definisi 2.2. [4] Aljabar fuzzy adalah sistem matematika $(F,+, \cdot)$ dengan operasi + dan - yang didefinisikan pada himpunan $F$, dimana untuk setiap a, $b, c \in F$ berlaku:

(1) $a+a=a$ dan $a \cdot a=a$,

(2) $a+b=b+a$ dan $a \cdot b=b \cdot a$,

(3) $a+(b+c)=(a+b)+c$ dan $a \cdot(b \cdot c)=(a \cdot b) \cdot c$,

(4) $a+(a \cdot b)=a$ dan $a \cdot(a+b)=a$,

(5) $a \cdot(b+c)=(a \cdot b)+(a \cdot c)$ dan $a+(b \cdot c)=(a+b) \cdot(a+c)$,

(6) terdapat $0 \in F$ sehingga $a+0=a$ dan $a \cdot 0=0$,

(7) terdapat $1 \in F$ sehingga $a+1=1$ dan $a \cdot 1=a$.

Selanjutnya, akan dijelaskan definisi dari matriks fuzzy dan sifat-sifat yang digunakan.

Definisi 2.3. [4] Matriks $A=\left[a_{i, j}\right]$ dikatakan matriks fuzzy jika $a_{i j} \in[0,1]$.

Definisi 2.4. [4] Misalkan $F_{m n}$ menunjukkan himpunan semua matriks fuzzy berukuran $m \times n$. Jika $m=n$, maka dapat ditulis dengan $F_{n}$.

Definisi 2.5. [4] Misalkan $A=\left[a_{i j}\right]$ dan $B=\left[b_{i j}\right]$ adalah matriks-matriks fuzzy berukuran $m \times n$, maka penjumlahan dari $A, B$ didefinisikan sebagai berikut,

$$
\begin{aligned}
A+B & =\left[a_{i j}+b_{i j}\right] \\
& =\left[\max \left\{a_{i j}, b_{i j}\right\}\right] .
\end{aligned}
$$

Definisi 2.6. [4] Misalkan $A=\left[a_{i k}\right]$ adalah matriks fuzzy berukuran $m \times p$ dan $B=$ $\left[b_{k j}\right]$ adalah matriks fuzzy berukuran $p \times n$, maka perkalian dari $A, B$ didefinisikan sebagai berikut,

$$
\begin{aligned}
A B & =\left[a_{i k} \cdot b_{k j}\right] \\
& =\left[\sum_{k=1}^{p} a_{i k}, b_{k j}\right] \\
& =\left[\max _{k}\left\{\min \left\{a_{i k}, b_{k j}\right\}\right\}\right] .
\end{aligned}
$$

Definisi 2.7. [4] Misalkan $A=\left[a_{i j}\right]$ adalah matriks fuzzy berukuran $m \times n, k \in$ $[0,1]$ dan $[0,1]$ adalah aljabar fuzzy, maka perkalian dari $k, A$ didefinisikan sebagai berikut,

$$
\begin{aligned}
k \cdot A & =\left[k \cdot a_{i j}\right] \\
& =\left[\min \left\{k, a_{i j}\right\}\right] .
\end{aligned}
$$

Definisi 2.8. [4] Misalkan $A=\left[a_{i j}\right]$ dan $B=\left[b_{i j}\right]$ adalah matriks-matriks fuzzy berukuran $m \times n$. Dikatakan $A \leq B$ apabila $a_{i j} \leq b_{i j}$ untuk setiap $i, j$.

Proposisi 2.9. [4] Misalkan $A, B, C \in F$ dengan ukuran masing-masing $m \times n, n \times$ $p$ dan $p \times q$, maka berlaku:

$$
(A B) C=A(B C) .
$$

Bagian ini akan menjelaskan pengertian dari idempoten dan matriks regular. 
Definisi 2.10. [6] Suatu Matriks fuzzy A berukuran $n \times n$ adalah idempoten jika dan hanya jika $A^{2}=A$.

Definisi 2.11. [4] Misalkan $A^{-}$adalah suatu g-invers dari $A$, matriks $A$ adalah regular jika memenuhi $A A^{-} A=A$.

\section{Pembahasan}

\subsection{Kesimilaran Semu Pada Matriks Fuzzy}

Definisi 3.1. [4] Matriks $A \in F_{m}$ dan $B \in F_{n}$ disebut sebagai kesimilaran semu, dinotasikan oleh $A \simeq B$, jika terdapat suatu matriks $X \in F_{m n}$ dan $Y \in F_{n m}$ sedemikian sehingga $A=X B Y, B=Y A X$, dan $X=X Y X$.

Lema 3.2. [4] Misalkan $A \in F_{m}$ dan $B \in F_{n}$, maka pernyataan berikut ekivalen:

(i) $A \simeq B$.

(ii) Terdapat $X \in F_{m n}$ dan $Y \in F_{n m}$ sedemikian sehingga $A=X B Y, B=Y A X$, dan $X Y \in F_{m}$ adalah idempoten.

(iii) Terdapat $X \in F_{m n}$ dan $Y \in F_{n m}$ sedemikian sehingga $A=X B Y, B=Y A X$, dan $Y X \in F_{n}$ adalah idempoten.

\section{Bukti.}

(i) $\Rightarrow$ (ii) dan (i) $\Rightarrow$ (iii) trivial, karena $X=X Y X$ maka $X Y \in F_{m}$ dan $Y X \in F_{n}$ adalah idempoten.

(ii) $\Rightarrow$ (i) $A=X B Y=(X Y) A(X Y)=(X Y X) B(Y X Y)$, dengan cara yang sama $B=Y A X=(Y X) B(Y X)=(Y X Y) B(X Y X)$, misal $X^{\prime}=$ $X Y X Y^{\prime}=Y X Y$, maka diperoleh: $A=X^{\prime} B Y^{\prime}$ dan $B=Y^{\prime} A X^{\prime}$. Selanjutnya, dengan menggunakan $X Y$ adalah idempoten maka $X^{\prime} Y^{\prime}=$ $(X Y X)(Y X Y)=(X Y)^{2}(X Y)=X Y\left(X^{\prime} Y^{\prime}\right)\left(X^{\prime} Y^{\prime}\right)=(X Y)(X Y)=$ $X Y=X^{\prime} Y^{\prime}$ sehingga diperoleh $X^{\prime} Y^{\prime}$ adalah idempoten. $A=X^{\prime} B Y^{\prime}=$ $X^{\prime}\left(Y^{\prime} A X^{\prime}\right) Y^{\prime}=\left(X^{\prime} Y^{\prime} X^{\prime}\right) B\left(Y^{\prime} X^{\prime} Y^{\prime}\right)$ dengan cara yang sama $B=Y^{\prime} A X^{\prime}=$ $\left(Y^{\prime} X^{\prime} Y^{\prime}\right) A\left(X^{\prime} Y^{\prime} X^{\prime}\right)$ misalkan $X^{\prime \prime}=X^{\prime} Y^{\prime} X^{\prime}$ dan $Y^{\prime \prime}=Y^{\prime} X^{\prime} Y^{\prime}$. Diperoleh $A=X^{\prime \prime} B Y^{\prime \prime}$ dan $B=Y^{\prime \prime} A X^{\prime \prime}$. Karena $X^{\prime} Y^{\prime}$ adalah idempoten, diperoleh $X^{\prime \prime} Y^{\prime \prime} X^{\prime \prime}=\left(X^{\prime} Y^{\prime} X^{\prime}\right)\left(Y^{\prime} X^{\prime} Y^{\prime}\right)\left(X^{\prime} Y^{\prime} X^{\prime}\right)=X^{\prime} Y^{\prime} X^{\prime}=X^{\prime \prime}$.

(iii) $\Rightarrow$ (i) Dapat dibuktikan dengan cara yang sama dengan di atas.

Teorema 3.3. [4] Misalkan $A \in F_{m}$ dan $B \in F_{n}$, maka pernyataan berikut ekivalen:

(i) $A \simeq B$.

(ii) Terdapat $X \in F_{m n}$ dan $Y \in F_{n m}$ sedemikian sehingga $A=X B Y, B=Y A X$, dan $(X Y)^{k} \in F_{m}$ adalah idempoten untuk suatu bilangan ganjil $k \in N$.

(iii) Terdapat $X \in F_{m n}$ dan $Y \in F_{n m}$ sedemikian sehingga $A=X B Y B=Y A X$, dan $(Y X)^{k} \in F_{n}$ adalah idempoten untuk suatu bilangan ganjil $k \in N$.

\section{Bukti.}


(i) $\Rightarrow$ (ii) Ikuti berdasarkan Lema 3.2.

(ii) $\Rightarrow$ (i) $A=X B Y=X(Y A X) Y=(X Y)(X B Y)(X Y)=$ $(X Y)^{2}(X B Y)(X Y)^{2}$, hingga dengan cara yang sama diperoleh $A=$ $(X Y)^{r}(X B Y)(X Y)^{r}$ dan $B=Y A X=Y(X B Y) X=(Y X)(Y A X)(Y X)=$ $Y(X Y)^{2} A(X Y)^{2} X$. Dengan cara yang sama diperoleh $B=Y(X Y)^{r} A(X Y)^{r} X$. Misalkan $X^{\prime}=(X Y)^{r} X$ dan $Y^{\prime}=Y(X Y)^{r}$ maka diperoleh $A=$ $(X Y)^{r}(X B Y)(X Y)^{r}=X^{\prime} B Y^{\prime}$ dan $B=Y(X Y)^{r} A(X Y)^{r} Y=Y^{\prime} A X^{\prime}$, misalkan $k=2 r+1$ dengan $r \in N$ diperoleh $X^{\prime} Y^{\prime}=\left[(X Y)^{r} X\right]\left[Y(X Y)^{r}\right]=$ $(X Y)^{2 r+1}=(X Y)^{k}$ idempoten. Berdasarkan Lema 3.2 maka $A \simeq B$ terbukti.

(i) $\Rightarrow$ (iii) Ikuti berdasarkan Lema 3.2.

(ii) $\Rightarrow$ (iii) Dapat dibuktikan dengan cara yang sama dengan di atas.

Akibat 3.4. [4] Misalkan $A \in F_{m}$ dan $B \in F_{n}$, maka pernyataan berikut ekivalen.

(i) $A \simeq B$.

(ii) Terdapat $X \in F_{m n}$ dan $Y \in F_{n m}$ sedemikian sehingga $A=X B Y, B=Y A X$, dan $\left[(X Y)^{k}=X Y\right] \in F_{m}$ untuk suatu $k \in N$ bilangan genap.

(iii) Terdapat $X \in F_{m n}$ dan $Y \in F_{n m}$ sedemikian sehingga $A=X B Y, B=Y A X$, dan $\left[(Y X)^{k}=Y X\right] \in F_{n}$ untuk suatu $k \in N$ bilangan genap.

\section{Bukti.}

(i) $\Rightarrow$ (ii) Ikuti berdasarkan Teorema 3.3.

(ii) $\Rightarrow$ (i) $(X Y)^{k}=X Y$ untuk suatu $k \in N$ bilangan genap. Misal $k=2 l$ untuk suatu $l \in N$, maka $(X Y)^{2 l}=X Y$, karena $(X Y)^{2 l}=(X Y)^{2 l-1}(X Y)$ sehingga $(X Y)^{2 l-1}(X Y)=X Y$. Selanjutnya $(X Y)^{2 l-1}(X Y)^{2 l-1}=(X Y)^{2 l-1}(X Y)(X Y)^{2(l-1)}=(X Y)(X Y)^{2(l-1)}=$ $(X Y)^{2 l-1}$. Jadi karena $(X Y)^{2 l-1}$ adalah idempoten berdasarkan Teorema 3.3, maka $A \simeq B$ terbukti.

(ii) $\Rightarrow$ (i) Dapat dibuktikan dengan cara yang sama dengan di atas.

Lema 3.5. [4] Misalkan $A \in F_{m}$ dan $B \in F_{n}$, maka pernyataan berikut ekivalen.

(i) $A \simeq B$.

(ii) Terdapat $X \in F_{m n}$ dan $Y \in F_{n m}$ sedemikian sehingga $A=X B Y, B=Y A X$, $X=X Y X$ dan $Y=Y X Y$.

(iii) Terdapat $X \in F_{m n}$ dan $Y, Z \in F_{n m}$ sedemikian sehingga $A=X B Y, B=$ $Z A X$, dan $X=X Y X=X Z X$.

\section{Bukti.}

(i) $\Rightarrow$ (iii) Karena $A \simeq B$, artinya terdapat $X \in F_{m n}$ dan $Y \in F_{n m}$ sedemikian sehingga $A=X B Y, B=Y A X$, dan $X=X Y X$. Pilih $Z \in F_{n m}$ dengan $Z=Y$, akibatnya $A=X B Y, B=Z A X$ dan $X=X Z X$.

(iii) $\Rightarrow$ (ii) $A=X B Y=X(Z A X) Y=(X Z) A(X Y)=X B(Y X Y)$ dan $B=Z A X=Z(X B Y) X=(Z X) B(Y X)=(Z X Z) A X$. Selanjutnya $X=$ 
$X Y X=(X Y X) Y(X Y X)=X(Y X Y) X$ dan dengan cara yang sama diperoleh $X=X Z X=X(Z X Z)(X Z X)=X(Z X Z) X$.

Misalkan $Y^{\prime}=Y X Y$ dan $Z^{\prime}=Z X Z$, maka diperoleh $X=X Y^{\prime} X$ dan $X=X Z^{\prime} X$. Akibatnya $A=X B Y^{\prime}$ dan $B=Z^{\prime} A X$.

Selanjutnya misalkan $Y^{\prime \prime}=Z^{\prime} X Y^{\prime}$, maka $X Y^{\prime \prime} X=X\left(Z^{\prime} X Y^{\prime}\right) X=$ $X Z^{\prime}\left(X Y^{\prime} X\right)=X Z^{\prime} X=X$ dan $Y^{\prime \prime} X Y^{\prime \prime}=\left(Z^{\prime} X Y^{\prime}\right) X\left(Z^{\prime} X Y^{\prime}\right)=$ $\left(Z^{\prime} X Y^{\prime}\right)\left(X Z^{\prime} X\right) Y^{\prime}=\left(Z^{\prime} X Y^{\prime}\right) X Y^{\prime}=Z^{\prime} X Y^{\prime}=Y^{\prime \prime}$. Selanjutnya, $X B Y^{\prime \prime}=$ $X B\left(Z^{\prime} X Y^{\prime}\right)=X\left(Z^{\prime} A X\right)\left(Z^{\prime} X Y^{\prime}\right)=X Z^{\prime} A\left(X Z^{\prime} X\right) Y^{\prime}=X\left(Z^{\prime} A X\right) Y^{\prime}=$ $X B Y^{\prime}=A$ dan $Y^{\prime \prime} A X=\left(Z^{\prime} X Y^{\prime}\right) A X=\left(Z^{\prime} X Y^{\prime}\right)\left(X B Y^{\prime}\right) X=$ $Z^{\prime}\left(X Y^{\prime} X\right) B Y^{\prime} X=Z^{\prime}\left(X B Y^{\prime}\right) X=Z^{\prime} A X=B$.

Jadi, karena terdapat $X \in F_{m n}, Y^{\prime \prime} \in F_{n m}$ sedemikian sehingga $A=X B Y^{\prime \prime}$, $B=Y^{\prime \prime} A X, X=X Y^{\prime \prime} X$, dan $Y^{\prime \prime}=Y^{\prime \prime} X Y^{\prime \prime}$.

(ii) $\Rightarrow$ (i) Jelas bahwa semua yang ada pada (ii) memenuhi (i) sehingga ini trivial.

Teorema 3.6. [4] Misalkan matriks $A \in F_{m}$ dan $B \in F_{n}$ sedemikian sehingga $A \simeq B$, maka $A$ adalah matriks regular jika dan hanya jika $B$ adalah matriks regular.

Bukti. $(\Rightarrow)$ Misal $A$ adalah matriks regular maka berdasarkan Definisi 2.11 terdapat $G \in F_{m}$ sedemikian sehingga $A G A=A$. Akan ditunjukkan $B$ adalah matriks regular, dengan menunjukkan $B U B=B$ untuk $U \in F_{n}$.

Karena $A \simeq B$, maka berdasarkan Lema 3.2 diperoleh $A=X B Y=X B(Y X Y)=$ $(X B Y) X Y=A X Y$ dan $A=X B Y=(X Y X) B Y=X Y(X B Y)=X Y A$. Misalkan $U=Y G X$ maka

$B U B=(Y A X)(Y G X)(Y A X)=(A X Y) G(X Y A) X=Y A G A X=Y(A G A) X=Y A X=B$.

Sehingga $B$ adalah matriks regular.

$(\Leftarrow)$ Dapat dibuktikan dengan cara yang sama dengan di atas.

Teorema 3.7. [4] Misalkan matriks $A \in F_{m}$ dan $B \in F_{n}$ sedemikian sehingga $A \simeq B$. Maka $A$ adalah idempoten jika dan hanya jika $B$ adalah idempoten.

Bukti. $(\Rightarrow)$ Misal $A$ adalah idempoten berarti $A^{2}=A$. Akibatnya,

$$
B^{2}=B B=(Y A X)(Y A X)=Y(A X Y) A X=Y A A X=Y A^{2} X=Y A X=B .
$$

Sehingga $B^{2}=B$ adalah idempoten.

$(\Leftarrow)$ Dapat dibuktikan dengan cara yang sama dengan di atas.

\section{Kesimpulan}

Berdasarkan pembahasan dalam tugas akhir ini, diperoleh sifat-sifat yang bersesuaian dengan kesimilaran semu pada matriks fuzzy $A$ dan $B$, yaitu sebagai berikut

(1) Misalkan $A \in F_{m}$ dan $B \in F_{n}$, maka pernyataan berikut ekivalen: 
(i) $A \simeq B$

(ii) Terdapat $X \in F_{m n}$ dan $Y \in F_{n m}$ sedemikian sehingga $A=X B Y, B=$ $Y A X$, dan $X Y \in F_{m}$ adalah idempoten.

(iii) Terdapat $X \in F_{m n}$ dan $Y \in F_{n m}$ sedemikian sehingga $A=X B Y, B=$ $Y A X$, dan $Y X \in F_{n}$ adalah idempoten.

(2) Misalkan $A \in F_{m}$ dan $B \in F_{n}$, maka pernyataan berikut ekivalen:

(i) $A \simeq B$.

(ii) Terdapat $X \in F_{m n}$ dan $Y \in F_{n m}$ sedemikian sehingga $A=X B Y, B=$ $Y A X$, dan $(X Y)^{k} \in F_{m}$ adalah idempoten untuk suatu bilangan ganjil $k \in N$.

(iii) Terdapat $X \in F_{m n}$ dan $Y \in F_{n m}$ sedemikian sehingga $A=X B Y B=$ $Y A X$, dan $(Y X)^{k} \in F_{n}$ adalah idempoten untuk suatu bilangan ganjil $k \in$ $N$.

(3) Misalkan $A \in F_{m}$ dan $B \in F_{n}$, maka pernyataan berikut ekivalen:

(i) $A \simeq B$.

(ii) Terdapat $X \in F_{m n}$ dan $Y \in F_{n m}$ sedemikian sehingga $A=X B Y, B=$ $Y A X$, dan $\left[(X Y)^{k}=X Y\right] \in F_{m}$ untuk suatu $k \in N$ bilangan genap.

(iii) Terdapat $X \in F_{m n}$ dan $Y \in F_{n m}$ sedemikian sehingga $A=X B Y, B=$ $Y A X$, dan $\left[(Y X)^{k}=Y X\right] \in F_{n}$ untuk suatu $k \in N$ bilangan genap.

(4) Misalkan $A \in F_{m}$ dan $B \in F_{n}$, maka pernyataan berikut ini ekivalen :

(i) $A \simeq B$.

(ii) Terdapat $X \in F_{m n}$ dan $Y \in F_{n m}$ sedemikian sehingga $A=X B Y, B=$ $Y A X, X=X Y X$ dan $Y=Y X Y$.

(iii) Terdapat $X \in F_{m n}$ dan $Y \in F_{n m}$ sedemikian sehingga $A=X B Y, B=$ $Z A X$, dan $X=X Y X=X Z X$.

(5) Misalkan matriks $A \in F_{m}$ dan $B \in F_{n}$ sedemikian sehingga $A \simeq B$. Maka $A$ adalah matriks regular jika dan hanya jika $B$ adalah matriks regular.

(6) Misalkan matriks $A \in F_{m}$ dan $B \in F_{n}$ sedemikian sehingga $A \simeq B$. Maka $A$ adalah idempoten jika dan hanya jika $B$ adalah idempoten.

\section{Ucapan Terima kasih}

Penulis mengucapkan terimakasih kepada ibu Hazmira Yozza, bapak I Made Arnawa, dan bapak Narwen yang telah memberikan masukan dan saran sehingga makalah ini dapat diselesaikan dengan baik.

\section{Daftar Pustaka}

[1] Ben-Israel, A and T.N.E Greville. 2003. Generalized Inverses Theory And Applications; Second Edition. Springer-Verlag New York, Inc, USA

[2] Kim, K.H and Roush, F.W. 1980. Generalized Fuzzy Matrices, Fuzzy Sets and Systems 4:293-315

[3] M.G. Thomson. 1977. Convergence of Power of A Fuzzy Matrix, Journal of Mathematical Analysis and Applications, 57:476-480 
[4] Meenakshi, A.R. 2008. Fuzzy Matrix Theory and Applications, MJP Publishers, India

[5] Meenakshi, A.R and Gandhimathi, T. 2015. Pseudo Similar Intuitionistic Fuzzy Matrices. Applied and Computational Mathematics. International Journal of Mathematics, 4:1-2

[6] Sidky, F.I and E.G. Enam. 1992. Some Remarks on Section of a Fuzzy Matrix, Journal of King Abdulaziz University Sci 4:145-155 